\title{
Effects of changeover contingencies on auditory stimulus control of two responses*
}

\author{
MARC N. BRANCH $\dagger$ and FREDERICK W. HEGGE $\dagger \dagger$ \\ Lniversity of Maryland, College Park, Maryland 20740
}

\begin{abstract}
Rats were exposed to a procedure in which auditory stimuli signaled which of two levers was associated with a variable-interval $60-\mathrm{sec}$ schedule of food presentation. Presses on the lever that was not associated with the variable-interval schedule ("errors") postponsd availability of reinforcement on the other lever by either a fixed number of responses or a fixed amount of time. Increasing the number of responses by which "errors" postponed food availability enhanced the level of stimulus control, and, after a relatively high degree of control had been achieved, reduction of the requirement had no effect. Control experiments ruled out extended exposure to the discrimination procedure as a factor in the increase in stimulus control and suggested that the time of introduction of a changeover contingency is an important determinant of its effect.
\end{abstract}

Procedures used to establish control of behavior by discriminative stimuli usually involve one response. The response is reinforced in the presence of one stimulus class, $\mathrm{SD}$, and not in the presence of another stimulus class, $S \Delta$. Under such procedures, no contingencies are specified during $\mathbf{S} \Delta$ and, therefore, it is not clear what behaviors are being controlled by $S \Delta$ or the extent to which these behaviors occur in the presence of $\mathrm{S}^{\mathrm{D}}$. Experiments that involve two responses can avoid this problem. If one response is reinforced in the presence of one set of stimuli and another in the presence of a second set, then measured and reinforced responses occur during both sets of stimuli and effects may be measured directly.

Discrimination procedures involving two responses are relatively common (e.g., Beecher \& Harrison, 1971), but most experiments have employed trials-type procedures in which only one response per stimulus presentation is allowed. Two-response procedures that involve free-operant responding have been used less frequently (e.g., Gollub, 1966; Cumming \& Eckerman, 1965). Perhaps the scarcity of free-operant two-response procedures in the study of stimulus control is due to a problem that arises when two responses are concurrently available to an organism in a free-operant situation; viz, the responses may not be completely independent. If schedules of reinforcement in which availability of reinforcement is determined by time (interval schedules) are used in two-response situations, certain manipulations are usually made to increase the independence of the two responses. Specifically, a requirement is instituted such that some time (a

*The authors wish to thank W. R. Farrow for his aid in running these experiments and J.W. McKearney for his helpful comments on earlier versions of the manuscript. Preparation of the manuscript was supported by Grant MH-18421 from NIMH.

+Now at the Department of Psychology, University of Florida, Gainesville, Florida 32611.

$\dagger$ Now at the Department of Experimental Psychophysiology, Walter Reed Army Institute of Research, Washington, D.C. 20012. changeover delay, or COD) must pass, after changing from one response to the other, before a response can be reinforced (cf. Hermstein, 1961).

It is possible that a changeover contingency will aid in establishing stimulus control of responding when two responses are available in a free-operant situation. The present experiments examined the effects of changeover contingencies in a two-response discrimination procedure.

\section{METHOD}

\section{Subjects}

Ss were five male rats derived from the Sprague-Dawley strain. Rats CM1, CM2, and CM3 were experimentally naive, whereas Rats CM4 and CM5 had served in an earlier experiment using fixed-ratio schedules. These two rats, however, had had no experience with the auditory stimuli or the apparatus used in the present experiment. The rats were kept in individual cages with continuous access to water and were maintained by restricted feeding to $80 \%$ of their mean free-feeding weights.

\section{Apparatus}

Experiments were conducted in a two-lever rat chamber (inside dimensions $22.2 \times 25.0 \times 16.5 \mathrm{~cm}$ ). The two side walls, the floor, and the ceiling were made of parallel stainless steel rods, $0.5 \mathrm{~cm}$ in diam, centered $2.3 \mathrm{~cm}$ apart. One of the remaining walls was made of Plexiglas, and the other wall, upon which the levers were mounted, was made of Plexiglas fronted by a sheet of stainless steel. Two stainless steel levers $(1.9 \times 2.0 \mathrm{~cm})$ were mounted $3.3 \mathrm{~cm}$ above the floor and were $10.2 \mathrm{~cm}$ apart, center to center. A downward force of $10 \mathrm{~g}$ on a lever operated a microswitch attached to that lever and was recorded as a response. A stainless steel foodcup $(1.2 \times 0.9 \times 0.5 \mathrm{~cm}$ deep) was located midway between the levers, $2.5 \mathrm{~cm}$ from the floor. Two $1.2 \mathrm{~W}$ lamps were located $3.5 \mathrm{~cm}$ above the top of the chamber, one directly over each lever. Also located $3.5 \mathrm{~cm}$ above the ceiling and directly over the foodcup was a tone generating device (Mallory Sonalert, Model SC628H) which, when operated, emitted a relatively pure $4.5-\mathrm{kHz}$ tone. The chamber was housed inside a plywood box lined with Celotex. White noise $(80 \mathrm{~dB}$ at $4 \mathrm{kHz})$ was provided in the room where the chamber was located. The experiment was monitored and controlled by relay switching and timing 
equipment located in an adjoining room. Sound levels (SPL) were measured using a Breul \& Kjaer Type 2203 precision sound-level meter, a Type 613 octave band filter set, and a Type 2801 condenser microphone power supply.

\section{Procedure}

Rats CM1, CM2, and CM3 were trained to press the two levers by shaping. The reinforcer was a $.045 \mathrm{gg}$ Noyes food pellet.

After two sessions, during which responses on either lever produced food pellets according to a variable-interval (VI) 20 -sec schedule (100 pellets per session), the basic experimental procedure was instituted. During the daily $2-\mathrm{h}$ sessions, food pellets were made available by a single VI 60 -sec schedule of reinforcement. There were 20 intervals in the VI schedule, generated from the "constant probability" formula presented by Catania and Reynolds $(1968$, p. 381). The lever associated with the VI 60-sec schedule alternated every $180 \mathrm{sec}$, on the average, with a range of 60 to $300 \mathrm{sec}$. The lever for which the VI was programmed at the beginning of each session was determined by a Gellerman (1933) series. When the VI schedule was in effect on the left lever, extinction was in effect on the right lever and vice versa. When the auditory stimuli were correlated with the $\mathrm{VI}$ and extinction contingencies and the VI schedule was in effect on the left lever, the $4.5-\mathrm{kHz}$ tone at $95 \mathrm{~dB}$ (re .0002 dynes $/ \mathrm{cm}^{2}$ ) was pulsed at a frequency of $2.5 \mathrm{~Hz}$ with a $50 \%$ duty cycle. When the VI was in effect on the right lever, the tone (at $95 \mathrm{~dB}$ during Sessions $1-8$ and at $80 \mathrm{~dB}$ for all remaining sessions) was pulsed at a frequency of $5 \mathrm{~Hz}$ with a $50 \%$ duty cycle. At any given time, responses on the lever associated with the VI were counted as "corrects." "Errors" and "corrects" were accumulated on individual electromagnetic counters for each lever.

Two main types of changeover contingencies were used. The first type, called a changeover ratio (COR), specified that following an "error" a fixed number of correct responses had to be emitted consecutively for food to be delivered. For example, if the value of the COR was 5 and the VI schedule determined that a reinforcer was available, then following an "error," delivery of food depended on the emission of six consecutive "correct" presses, i.e., "errors" postponed food availability by five presses. The second type of changeover contingency, a changeover delay (COD), specified that food could not be delivered after a "correct" press uniess a fixed period of time following an "error" had passed. That is, each "error" started a timer that prevented the delivery of food. The changeover requirements were not affected when the lever on which the VI schedule was programmed changed. For example, if the changeover requirement was $C O R=15$ and the VI schedule changed from one lever to another, and the rat had made an "emor" followed by seven "correct" presses before the schedule changed, then eight more "correct" presses on the lever were needed to complete the COR. In one condition for Rats CM4 and CM5, a different type of COD was used. Under this procedure (denoted as COD*), the first "correct" press following an "error" started a timer that prevented the delivery of food until a fixed period of time had elapsed. The main difference between the regular $C O D$ and the $C O D^{*}$ procedures was that in the former the delay was timed for the last "error" and in the latter the delay was timed from the first "correct" following an "error."

Rats CM1, CM2, and CM3 were exposed to an ascending series of $C O R$ values and then to the smallest COR value again. The tones were correlated with the $\mathrm{VI}$ and extinction contingencies for Rats CM1 and CM2 but not for Rat CM3 during exposure to these COR contingencies. These three rats were finally exposed to a procedure with a COD of $7.5 \mathrm{sec}$, and the tones were correlated with the schedule contingencies for all three rats.

Following two sessions of exposure to a procedure under which presses on either lever produced food according to the VI 60-sec schedule, Rats CM4 and CM5 were given extended exposure to the smallest COR value. Following this training, these two rats were exposed to several changeover contingencies and, finally, one session in which the tones were absent was conducted. A summary of the procedures for all rats appears in Table 1 .

\section{RESULTS}

The change in intensity of one of the sets of tone stimuli after eight sessions was instituted because there was little evidence of stimulus control under a $2: 1$ pulsed-tone repetition rate difference with duty cycle held constant. Within two sessions after the introduction of a 15-dB intensity difference, the data for both CM1 and CM2 showed evidence of increased stimulus control.

Table 1 gives mean data from the last three sessions of each condition for each animal. The last column shows that lever preference (proportion of responses on the right lever) did not change systematically with changes in the changeover requirement. Also evident from the table is that, in one case, percent correct on the individual levers differed by more than 10\% (Rat $\mathrm{CM} 2, \mathrm{COR}=5$ ) and, in several other instances, by more than $5 \%$. Altering the changeover requirement, however, virtually always produced similar effects on the individual levers. Due to the comparability of effects on individual levers and since daily values of percent correct on both levers were somewhat more stable than the values for individual levers, the data are discussed in terms of total percent correct responses.

The main results of the experiments with Rats CM1, $\mathrm{CM} 2$, and $\mathrm{CM} 3$ are shown in Fig. 1. Both Rat CM1 and Rat CM2 made about $60 \%$ correct responses when the changeover ratio was one press at the beginning of the experiment. Over the last eight sessions of this condition, the data from Rat CM1 showed a slight decreasing trend in percent correct, while, over the same period, the data from Rat $\mathrm{CMl}$ showed no trend. When the $\mathrm{COR}$ value was changed to 5 , the data from both rats showed increases in the percentage of corrects and, when the contingency was changed to $C O R=15$, the behavior of Rat CM2 showed another increase. Increasing the number of presses between errors and food delivery had no effect on the mean level of percent correct responses for Rat $\mathrm{CM} 3$, for which the tone stimuli were not correlated with the VI and extinction contingencies. When the COR was 15, however, the behavior of this rat did show an increase in session to session variability.

In the fourth phase of the experiments with Rats CM1, CM2, and CM3, the COR value was returned to one press. Neither the behavior of Rat CM1 nor that of Rat CM2 showed any substantial change in stimulus control after this manipulation was made.

Although quantitative data on changeovers were not obtained, observation of Rats CM1 and CM2 indicated that increasing the COR produced an increase in the 
Table 1

Mean Data from the Last Three Sessions of Each Condition

\begin{tabular}{|c|c|c|c|c|c|c|c|c|}
\hline \multirow[b]{2}{*}{ Rat } & \multirow{2}{*}{$\begin{array}{c}\text { Tones } \\
\text { Correlated? }\end{array}$} & \multirow{2}{*}{$\begin{array}{l}\text { Changeover } \\
\text { Contingency }\end{array}$} & \multirow[b]{2}{*}{ Sessions } & \multicolumn{2}{|c|}{ Left Presses $\left(R_{L}\right)$} & \multicolumn{2}{|c|}{ Right Presses $\left(\mathbf{R}_{\mathbf{R}}\right)$} & \multirow{2}{*}{$\frac{\mathbf{R}_{\mathbf{R}}}{\mathrm{R}_{\mathbf{R}}+\mathrm{R}_{\mathbf{L}}}$} \\
\hline & & & & Correct & Incorrect & Correct & Incorrect & \\
\hline CM1 & $\begin{array}{l}\text { Yes } \\
\text { Yes } \\
\text { Yes } \\
\text { Yes } \\
\text { Yes }\end{array}$ & $\begin{array}{l}C O R=1 \\
C O R=5 \\
C O R=15 \\
C O R=1 \\
C O D=7.5 \mathrm{sec}\end{array}$ & $\begin{array}{l}18 \\
24 \\
17 \\
13 \\
19\end{array}$ & $\begin{array}{l}2278 \\
4296 \\
4239 \\
3796 \\
2988\end{array}$ & $\begin{array}{r}1652 \\
803 \\
583 \\
570 \\
618\end{array}$ & $\begin{array}{l}3584 \\
4158 \\
4565 \\
3479 \\
4235\end{array}$ & $\begin{array}{r}2226 \\
996 \\
1094 \\
418 \\
817\end{array}$ & $\begin{array}{l}.596 \\
.503 \\
.540 \\
.472 \\
.584\end{array}$ \\
\hline $\mathrm{CM} 2$ & $\begin{array}{l}\text { Yes } \\
\text { Yes } \\
\text { Yes } \\
\text { Yes } \\
\text { Yes }\end{array}$ & $\begin{array}{l}\mathrm{COR}=1 \\
\mathrm{COR}=5 \\
\mathrm{COR}=15 \\
\mathrm{COR}=1 \\
\mathrm{COD}=7.5 \mathrm{sec}\end{array}$ & $\begin{array}{l}20 \\
24 \\
17 \\
13 \\
20\end{array}$ & $\begin{array}{l}2539 \\
3103 \\
3489 \\
1569 \\
1171\end{array}$ & $\begin{array}{r}1278 \\
861 \\
517 \\
313 \\
126\end{array}$ & $\begin{array}{l}3020 \\
4551 \\
3828 \\
2042 \\
2821\end{array}$ & $\begin{array}{r}2208 \\
2303 \\
968 \\
619 \\
427\end{array}$ & $\begin{array}{l}.578 \\
.634 \\
.545 \\
.586 \\
.715\end{array}$ \\
\hline $\mathrm{CM} 3$ & $\begin{array}{l}\text { No } \\
\text { No } \\
\text { No } \\
\text { No } \\
\text { Yes }\end{array}$ & $\begin{array}{l}C O R=1 \\
C O R=5 \\
C O R=15 \\
C O R=1 \\
C O D=7.5 \mathrm{sec}\end{array}$ & $\begin{array}{l}20 \\
24 \\
17 \\
13 \\
20\end{array}$ & $\begin{array}{l}2386 \\
2713 \\
3242 \\
2136 \\
2566\end{array}$ & $\begin{array}{r}2258 \\
2399 \\
2614 \\
1879 \\
683\end{array}$ & $\begin{array}{l}2733 \\
1993 \\
2510 \\
1554 \\
3009\end{array}$ & $\begin{array}{r}2867 \\
2198 \\
2571 \\
1717 \\
924\end{array}$ & $\begin{array}{l}.547 \\
.450 \\
.464 \\
.449 \\
.548\end{array}$ \\
\hline CM4 & $\begin{array}{c}\text { Yes } \\
\text { Yes } \\
\text { Yes } \\
\text { Yes } \\
\text { Yes } \\
\text { Yes } \\
\text { No Tones }\end{array}$ & $\begin{array}{l}C O R=1 \\
C O D=5 \mathrm{sec} \\
C O D=10 \mathrm{sec} \\
C O D^{*}=10 \mathrm{sec} \\
C O R=10 \\
C O R=20 \\
C O R=20\end{array}$ & $\begin{array}{r}53 \\
10 \\
10 \\
15 \\
11 \\
10 \\
1\end{array}$ & $\begin{array}{l}1402 \\
1866 \\
1613 \\
2090 \\
1884 \\
2508 \\
2105\end{array}$ & $\begin{array}{r}507 \\
749 \\
672 \\
947 \\
925 \\
1083 \\
1719\end{array}$ & $\begin{array}{l}1626 \\
2046 \\
2767 \\
2922 \\
2373 \\
2476 \\
2070\end{array}$ & $\begin{array}{r}708 \\
1010 \\
1572 \\
1400 \\
1221 \\
1298 \\
1864\end{array}$ & $\begin{array}{l}.550 \\
.539 \\
.655 \\
.587 \\
.561 \\
.512 \\
.507\end{array}$ \\
\hline CM5 & $\begin{array}{c}\text { Yes } \\
\text { Yes } \\
\text { Yes } \\
\text { Yes } \\
\text { Yes } \\
\text { Yes } \\
\text { No Tones }\end{array}$ & $\begin{array}{l}\text { COR }=1 \\
C O D=5 \mathrm{sec} \\
C O D=10 \mathrm{sec} \\
C O D^{*}=10 \mathrm{sec} \\
\mathrm{COR}=10 \\
\mathrm{COR}=20 \\
\mathrm{COR}=20\end{array}$ & $\begin{array}{r}54 \\
10 \\
10 \\
14 \\
11 \\
10 \\
1\end{array}$ & $\begin{array}{r}970 \\
1124 \\
1233 \\
1073 \\
1107 \\
1246 \\
1412\end{array}$ & $\begin{array}{r}671 \\
620 \\
753 \\
683 \\
622 \\
738 \\
1120\end{array}$ & $\begin{array}{r}844 \\
949 \\
924 \\
1401 \\
1540 \\
1358 \\
1454\end{array}$ & $\begin{array}{r}701 \\
706 \\
660 \\
1144 \\
1355 \\
1271 \\
1317\end{array}$ & $\begin{array}{l}.485 \\
.487 \\
.444 \\
.592 \\
.626 \\
.570 \\
.522\end{array}$ \\
\hline
\end{tabular}

number of presses per visit to each lever. When the COR was returned to one press, no obvious change in the number of presses per visit was observed.

In the final phase of the experiments with Rats CM1, $\mathrm{CM} 2$, and $\mathrm{CM} 3$, a COD was employed, and the tone stimuli were correlated with the VI and extinction contingencies for Rat CM3. The behavior of Rat CM3 came under stimulus control even though this rat had been trained for 74 sessions under conditions in which the tone stimuli were irrelevant with respect to the schedules.

In order to control for the possibility that the increase in percent correct responses shown in the behavior of Rats CM1 and CM2 was due merely to prolonged exposure to the discriminative stimuli and not to the changes in COR values, Rats CM4 and CM5 were given extended training with a COR value of one press. The data from these two rats are presented in Fig. 2. There was no long-term, or gradual, increase in stimulus control of leverpressing with extended exposure to the condition in which errors postponed delivery of food by a single response. After long exposure to the condition with $\mathrm{COR}=1$, institution of several CODs and of two large COR values did not produce an increase in stimulus control for Rats CM4 and CM5. The only effect of these changes on percentage correct was to increase the session to session variability.
Table 1 shows that overall response rates for Rats CM4 and CM5 were somewhat lower than the rates for Rats CM1 and CM2. The comparatively low rates shown by Rats CM4 and CM5 developed over the course of long exposure to the condition with $\mathrm{COR}=1$. The mean numbers of total responses for these two rats for Sessions 18-20 (about the same number of sessions that Rats CM1 and CM2 were initially exposed to the condition with $\mathrm{COR}=1$ ) were 7,050 for Rat CM4 and 6,317 for Rat CM5. Thus, long exposure to the condition with $\mathrm{COR}=1$ did not produce increases in percent correct but did produce a lowering of overall response rate.

The final session for Rat CM4 and CM5 was conducted with the tone stimuli absent in order to determine whether the tones were controlling the behavior of these two rats. The points in Fig. 2 labeled "NT" are from this session, and they show that when the tones were removed percent correct values dropped to near chance levels.

\section{DISCUSSION}

The present results clearly show that increasing the delay between incorrect responses and food delivery can enhance the establishment of stimulus control. The institution of changeover contingencies, however, did 


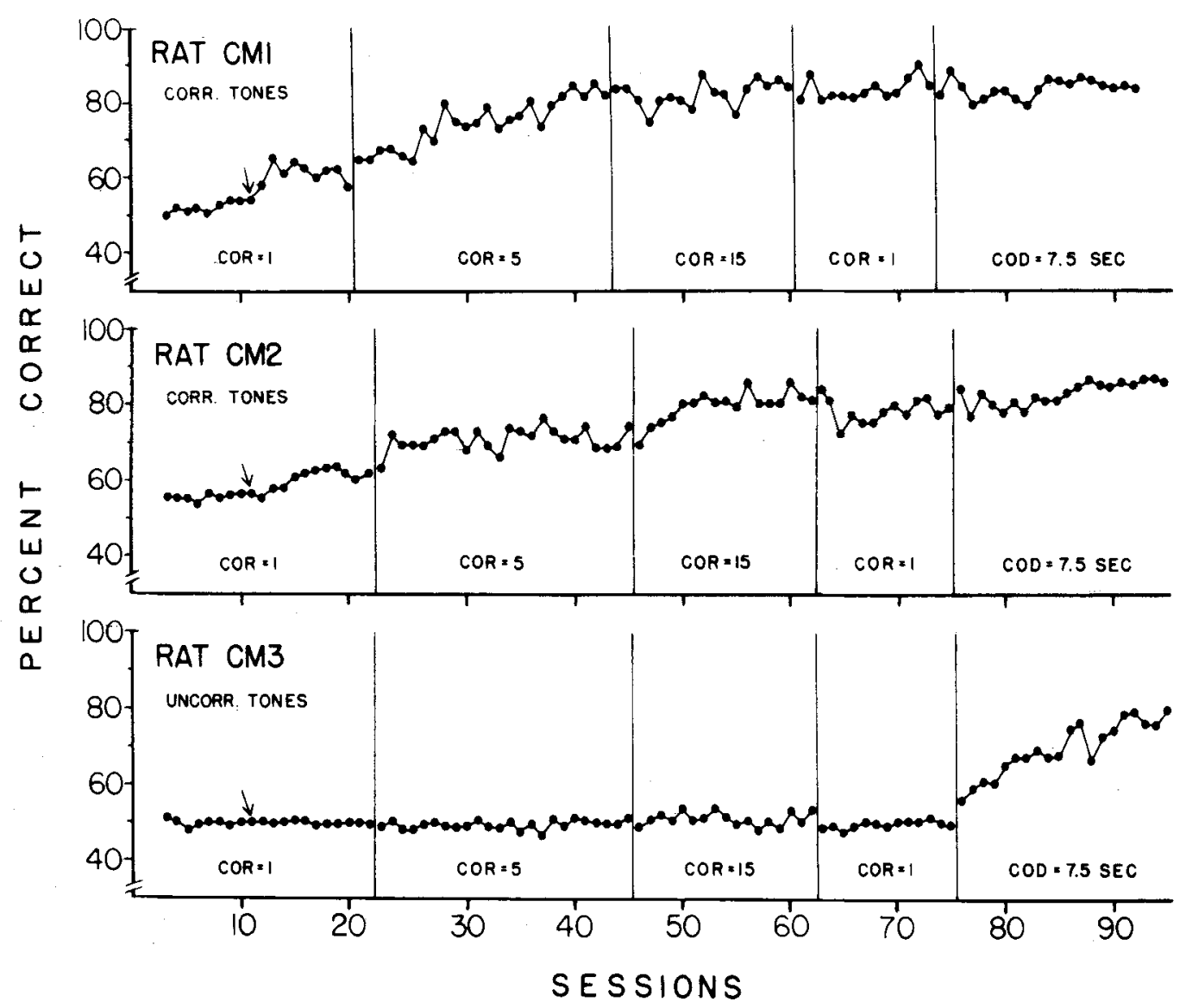

Fig. 1. Percent correct responses over sessions. Each point is the mean from a session. The vertical bars show where the procedure was changed. The arrows indicate the points from the first session in which the intensities of the tones were different.

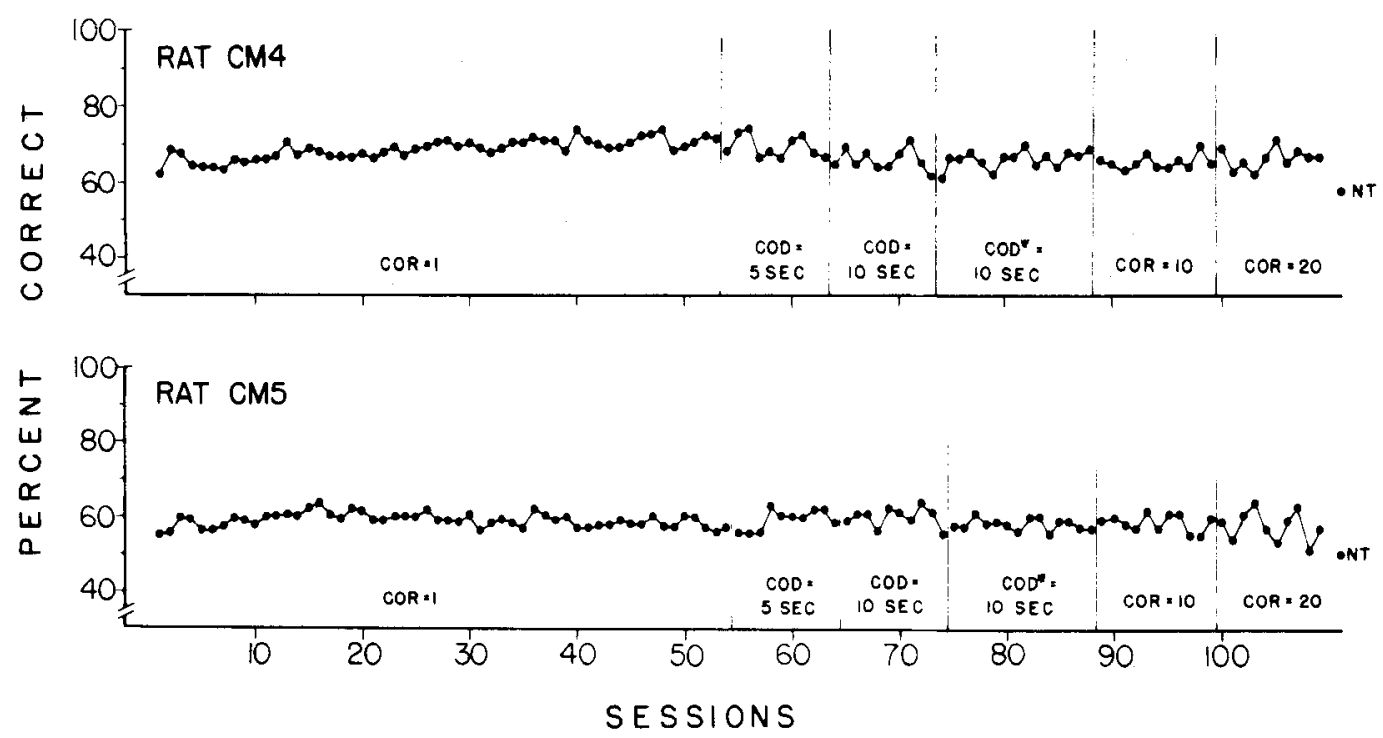

Fig. 2. Percent correct responses over sessions, Each point is the mean from a session, and the vertical bars show when the procedure was changed. The asterisk indicates that the COD was timed from the first correct press following an error rather than from each error.

not produce increases in stimulus control in rats with a prolonged history of exposure to the discrimination procedure. The response rates of Rats CM4 and CM5 decreased over long exposure to a COR of one press. It is possible that the low response rates occurring at the end of that condition $(\mathrm{COR}=1)$ played a role in blocking the enhancement of stimulus control. but it is not clear how these low rates may have produced such an effect. 
Perhaps these low rates reflect an increase in some pattern of unrecorded behavior that interfered with the strengthening of stimulus control of leverpressing.

These data are consistent with a large body of data that point to the importance of behavioral histories in determining future performance. There have been many experiments that show that experience with electric shock (e.g., Morse \& Kelleher, 1970) or with schedules of positive reinforcement (e.g., Ferster \& Skinner, 1957) is an important determinant of later behavior.

The data from Rat CM3 suggest that long exposure to a procedure in which no stimulus control is achieved does not block the acquisition of stimulus control, even if the stimuli have been present but irrelevant. These data also suggest that the failure to obtain increases in stimulus control with the addition of changeover contingencies for Rats CM4 and CM5 was not due simply to extended exposure to a two-lever procedure.

A comparison of the data from Rat CM3 and those from Rats CM4 and CM5 provides some insight into what type of behavioral history is necessary to block the enhancing effects of changeover contingencies on stimulus control. As the data from the session in which the tones were absent for Rats CM4 and CM5 show, the behavior of these two animals was, in fact, under some control by the tone stimuli. The behavior of Rat CM3, on the other hand, showed no differential control by the stimuli until they were correlated with the VI and extinction stimuli. This suggests that the behavior patterns established in Rats CM4 and CM5 were under the control of the tone stimuli, and these same patterns continued to occur under the control of the tone stimuli, even after relatively large CODs and CORs were introduced. Put simply, it may be that long exposure to a procedure that produces a small amount of stimulus control retards increases in control by the same stimuli more than does long exposure to a procedure that produces no control by the stimuli.

Perhaps an important feature of the stimuli and schedules used in these experiments is that, even when stimulus control was obtained, the level of accuracy was considerably less than $100 \%$ correct. It is possible that the irreversibility of some of the effects was due, in part, to the fact that the procedure was one that produced only an intermediate level of stimulus control. Of two previous experiments in which two responses were available in a free-operant discrimination procedure, one showed much better stimulus control than that shown here and the other showed comparable stimulus control. The first experiment (Cumming \& Eckerman, 1965) used pigeons as Ss and intensities of light as stimuli. A high level of stimulus control was obtained in this experiment, in which pigeons pecked near the ends of a 10-in. (25.4-cm) strip of pigeon keys. In the second experiment (Gollub, 1966), rats were trained to poke their noses into either end of a 10 -in. $(25.4-\mathrm{cm})$ slit, the appropriate end being signaled by the frequency of clicks emitted from a speaker behind the slit. Gollub reported levels of stimulus control comparable to the ones obtained with Rats CM1 and CM2. Gollub's experiment, however, employed a variable-ratio schedule of reinforcement and may not be comparable. In neither of these experiments was a changeover contingency used. Gollub (personal communication), however, has shown that a distance of about 8 in. $(20.3 \mathrm{~cm})$ between operanda can act in the same way as a COD in pigeons. The distances between response locations in the experiments by Cumming and Eckerman (1965) and by Gollub (1966) were probably functioning as effective CODs.

The data from the present experiment suggest that, when VI schedules are used to produce auditory stimulus control in rats, a contingency that insures a delay between "incorrect" responses and reinforcement will facilitate the development of stimulus control, provided that the changeover contingency is instituted early in training. The data further suggest that, once stimulus control has been established with the aid of a changeover contingency, the contingency may no longer be necessary.

\section{REFERENCES}

Beecher, M. D., \& Harrison, J. M. Rapid acquisition of an auditory localization discrimination by rats. Journal of the Experimental Analysis of Behavior, 1971, 16, 193-199.

Catania, A. C., \& Reynolds, G. S. A quantitative analysis of the responding maintained by interval schedules of reinforcement. Journal of the Experimental Analysis of Behavior, 1968, 11, 327-383.

Cumming, W. W., \& Eckerman, D. A. Stimulus control of a differentiated operant. Psychonomic Science, 1965, 3, 313-314.

Ferster, C. B., \& Skinner, B. F. Schedules of reinforcement. New York: Appleton-Century-Crofts, 1957.

Gellerman, L. W. Chance orders for alternating stimuli in visual discrimination experiments. Journal of Genetic Psychology, 1933, 42, 206-208.

Gollub, L. R. Stimulus generalization of response-position in the rat. Psychonomic Science, 1966, 6, 433-434.

Herrnstein, R. J. Relative and absolute strength of response as a function of frequency of reinforcement. Journal of the Experimental Analy sis of Behavior, 1961, 4, 267-272.

Morse, W. H., \& Kelleher, R. T. Schedules as fundamental determinants of behavior. In W. N. Schoenfeld (Ed.), The theory of reinforcement schedules. New York: Appleton-Century-Crofts, 1970. Pp. 139-185.

(Received for publication May 14, 1973; accepted September 11, 1973.) 